\title{
Phylogeography and population history of the least weasel (Mustela nivalis) in the Palearctic based on multilocus analysis
}

\author{
Takuma Sato $^{1}$ (D) | Alexei V. Abramov ${ }^{2}$ (D) | Evgeniy G. Raichev ${ }^{3}$ | Pavel A. Kosintsev ${ }^{4,5}$ | \\ Risto Väinölä ${ }^{6}$ | Takahiro Murakami ${ }^{7}$ | Yayoi Kaneko ${ }^{8}$ | Ryuichi Masuda ${ }^{1,9}$
}

${ }^{1}$ Department of Natural History Sciences, Graduate School of Science, Hokkaido University, Sapporo, Japan

${ }^{2}$ Zoological Institute, Russian Academy of Sciences, St. Petersburg, Russia

${ }^{3}$ Agricultural Faculty, Trakia University, Stara Zagora, Bulgaria

${ }^{4}$ Institute of Plant and Animal Ecology, Ural Branch, Russian Academy of Sciences,

Ekaterinburg, Russia

${ }^{5}$ Ural Federal University, Ekaterinburg, Russia

${ }^{6}$ Finnish Museum of Natural

History, University of Helsinki, Helsinki, Finland

${ }^{7}$ Shiretoko Museum, Shari, Japan

${ }^{8}$ Faculty of Agriculture, Tokyo University of Agriculture and Technology, Fuchu, Japan

${ }^{9}$ Department of Biological Sciences, Faculty of Science, Hokkaido University, Sapporo, Japan

\section{Correspondence}

Ryuichi Masuda, Department of Biological Sciences, Faculty of Science, Hokkaido University, Sapporo 060-0810, Japan.

Email: masudary@sci.hokudai.ac.jp

\section{Funding information}

Russian Foundation for Basic

Research, Grant/Award Number:

AAAA-A17-117022810195-3; Japan Arctic

Research Network Center; Japan Society of the Promotion of Science (JSPS)

\begin{abstract}
The least weasel (Mustela nivalis) is one of the most widely distributed carnivorans. While previous studies have identified distinct western and eastern mitochondrial DNA (mtDNA) lineages of the species in the western Palearctic, their broader distributions across the Palearctic have remained unknown. To address the broad-scale phylogeographical structure, we expanded the sampling to populations in Eastern Europe, the Urals, the Russian Far East, and Japan, and analyzed the mtDNA control region and cytochrome $b$, the final intron of the zinc finger protein on $Y$ chromosome ( $Z F Y$ ), and the autosomal agouti signaling protein gene (ASIP). The mtDNA data analysis exposed the previous western lineage (Clade I) but poorly supported assemblage extending across Palearctic, whereas the previous eastern lineage (Clade II) was reconfirmed and limited in the south western part of the Palearctic. The ZFY phylogeny showed a distinctive split that corresponding to the mtDNA lineage split, although less phylogeographical structure was seen in the ASIP variation. Our data concur with the previous inference of the Black Sea-Caspian Sea area having an ancestral character. The Urals region harbored high mitochondrial diversity, with an estimated coalescent time of around 100,000 years, suggesting this could have been a cryptic refugium. Based on the coalescent-based demographic reconstructions, the expansion of Clade I across the Palearctic was remarkably rapid, while Clade II was relatively stable for a longer time. It seems that Clade II has maintained a constant population size in the temperate region, and the expansive Clade I represents adaptation to the cold regions.
\end{abstract}

KEYWORDS

ASIP, least weasel, mitochondrial DNA, Mustela nivalis, ZFY 


\section{1 | INTRODUCTION}

Some species have narrow distributions within limited geographic regions, while others are distributed broadly across the globe. A basic concern of biogeographical science is to understand how species have evolved and acquired their worldwide distributions. Phylogeography explores the evolutionary and dispersal histories of widespread species using the genealogical information embedded in their DNA (Garrick et al., 2015). Many studies of phylogeography have tried to reconstruct the migration histories of mammalian species in the Palearctic and to identify their glacial refugia, which have frequently been located in the Balkan and Iberian peninsulas, in the Caucasus and the Russian Far East (Frantz et al., 2014; Hewitt, 1999; Hope et al., 2010; Korsten et al., 2009). The location of these refugia evidently reflects the species' environmental tolerances (Schmitt \& Varga, 2012). Moreover, Řičánková, Robovský, Riegert, and Zrzavý (2015) pointed out that Central Asia was important as a glacial refugium for the megafauna and that the "mammoth fauna" (these were the cold tolerant fauna, which developed and reached their peak during the late Pleistocene, see Vereshchagin \& Baryshnikov, 1992) remained there with highest frequency in Palearctic.

The least weasel (Mustela nivalis Linnaeus, 1766) is one of the most widespread carnivore taxa in the Northern Hemisphere with a range covering most of the Palearctic: Europe, North Africa, Northern Asia including the Japanese islands, and North America. Considering this fossil records, the least weasel is included in the "mammoth fauna" (Sheffield \& King, 1994; Youngman, 1993, and references therein). This species is considered a mesopredator, and their diet consists mainly of rodents, lagomorphs with some insects (King \& Powell, 2007). The least weasel has significant variation in body and skull sizes and proportions throughout its huge distribution range (Abramov \& Baryshnikov, 2000). Along with an overall high variation of cranial characters, there is a tendency toward an increase in body size and relative tail length from the north to south and to some extent from the east to west (Abramov \& Baryshnikov, 2000). Abramov and Baryshnikov also suggested the least weasel has unique geographical variations such as the distribution of the two pelage colorations (nivalis and vulgaris): The nivalis type is distributed in northern Palearctic and the vulgaris type in the Mediterranean region, and the ancestral cranial type, in turn, is distributed in Northern Africa, Spain, Caucasus, Middle East, and Central Asia. It is also remarkable that the body sizes of the least weasels do not follow the Bergmann rule (Bergmann, 1847). King and Powell (2007) suggested that this phenomenon is affected by the unique evolutionary process of the least weasels, which have decreased their body sizes so that they can prevent the heat loss and forage the small rodents in the cold environment. In fact, Marciszak and Socha (2014) reported a correlation between the temperature and the cranial size using the fossil materials from Polish caves: The size decreases during colder periods and increases in warmer intervals. In addition, Zub, Szafrańska, Konarzewski, and Speakman (2011) suggested the winter survival rate is higher for smaller than for larger least weasels. It is plausible that several weasel characters including the ecological status, comprehensive distribution, and great geographical variation have resulted from adaptation to the various environments, and it is interesting to further understand the evolutionary history of the least weasel.

The chromosome number of the least weasel in Siberia and in Hokkaido, Japan, is $2 n=42$, whereas on the Honshu Island it is $2 n=38$ (Mandahl \& Fredga, 1980; Obara, 1991). Distinct mitochondrial DNA (mtDNA) control region $(C R)$ sequences were observed in least weasels from Hokkaido and Honshu islands, as reported by Kurose, Masuda, and Yoshida (1999). In a phylogeographic analysis of the mtDNA CR across Siberia, the Caucasus, Central Asia, and North America, the lineages around the Caucasus were the most variable probably due to the introgression or maintenance of polymorphic status of their ancestral population (Kurose, Abramov, \& Masuda, 2005). Meanwhile, Lebarbenchon, Poitevin, Arnal, and Montgelard (2010) detected a subdivision of the Western Palearctic least weasel mitochondrial diversity into Western (Clade I) and Eastern (Clade II) lineages using the mtDNA CR and cytochrome $b$ (Cytb) sequences. Using only Cytb data, Mcdevitt et al. (2012) identified a presence of a suture zone between the lineages in Poland and suggested that the Carpathians were one of the refugia for the least weasel and confirmed the existence of the two main lineages, similar to the western Palearctic region reported by Lebarbenchon et al. (2010). Rodrigues et al. (2016) revealed the taxonomic status of the Egyptian least weasel that shared a haplotype with weasels in Turkey and Mediterranean islands. Additionally, the least weasel could have been imported to some Mediterranean islands artificially, and the gene flow could have affected the genetic structure (Lebarbenchon et al., 2010; Rodrigues et al., 2017). However, the original dispersal and migration history of the least weasels still remains unclear in Palearctic.

To further understand the molecular phylogenetic and biogeographical relationships among least weasels, we have analyzed mtDNA $C R$ and $C y t b$, as maternally inherited genes, from a range of new localities across the Palearctic region. In addition, we also sequenced and analyzed the final intron of the zinc finger protein locus on the $Y$ chromosome ( $Z F Y$ ) as a paternally inherited gene and the agouti signaling protein locus (ASIP) as a biparentally inherited gene. Combining our data with the previous results, we discuss the phylogeography and migration history of the least weasel in Palearctic

\section{2 | MATERIALS AND METHODS}

\section{1 | Specimens}

Tissue samples were obtained from collaborative laboratories and museums in Bulgaria, Russia, Finland, and Japan (76 samples consisting of 65 ethanol-preserved muscle tissues and 11 dried skins; Table 1 and Figure 1). Of these, 31 were also used in the previous mtDNA CR studies of Kurose et al. (1999), Kurose et al. (2005). In 
TAB LE 1 Geographic origins and accession numbers of samples examined in this study

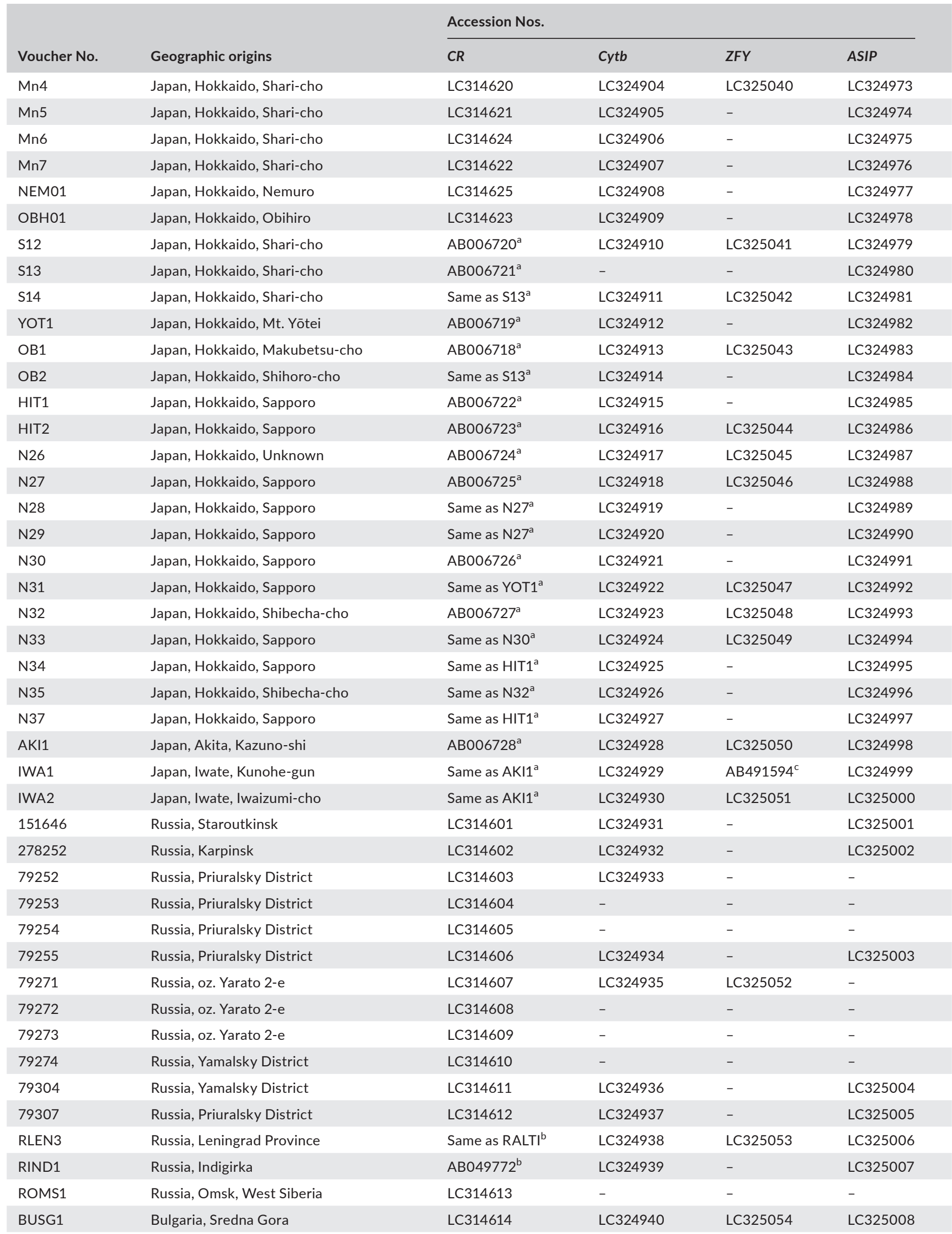


TABLE 1 (Continued)

\begin{tabular}{|c|c|c|c|c|c|}
\hline Voucher No. & Geographic origins & \multicolumn{4}{|l|}{ Accession Nos. } \\
\hline BUV1 & Bulgaria, Varna & LC314615 & LC324941 & LC325055 & LC325009 \\
\hline BUV2 & Bulgaria, Varna & LC314616 & LC324942 & LC325056 & LC325010 \\
\hline BUV3 & Bulgaria, Varna & LC314617 & LC324943 & LC325057 & LC325011 \\
\hline BUV4 & Bulgaria, Varna & LC314618 & LC324944 & LC325058 & LC325012 \\
\hline RTUR2 & Turkmenistan, Murgab & Same as RCAU $1^{\text {b }}$ & LC324946 & - & LC325014 \\
\hline RKAR2 & Turkmenistan, South East Karakum & $\mathrm{AB} 049774^{\mathrm{b}}$ & LC324947 & - & LC325015 \\
\hline RASK1 & Ukraine, Askania, Nova & $\mathrm{AB} 049765^{\mathrm{b}}$ & LC324948 & - & LC325016 \\
\hline RASK2 & Ukraine, Askania, Nova & $\mathrm{AB} 049768^{\mathrm{b}}$ & LC324949 & - & LC325017 \\
\hline KS.KN 39356 & Finland, Porvoon mlk & LC314626 & LC324953 & LC325060 & LC325020 \\
\hline KS.KN 39357 & Finland, Joutsa & LC314627 & LC324954 & LC325061 & LC325021 \\
\hline KS.KN 34388 & Finland, Siuntio & LC314628 & LC324955 & - & LC325022 \\
\hline KS.KN 34462 & Finland, Helsinki, Vuosaari & LC314629 & LC324956 & - & LC325023 \\
\hline KS.KN 34463 & Finland, Inkoo & LC314630 & LC324957 & - & LC325024 \\
\hline KS.KN 39310 & Finland, Heinolan mlk & LC314631 & LC324958 & - & LC325025 \\
\hline KS.KN 34644 & Finland, Vantaa, Korso & LC314632 & LC324959 & - & LC325026 \\
\hline KS.KN 38719 & Finland, Siuntio & LC314633 & LC324960 & - & LC325027 \\
\hline KS.KN 34740 & Finland, Vihti, Selki & LC314634 & LC324961 & - & LC325028 \\
\hline KS.KN 47874 & Finland, Tampere & LC314640 & LC324967 & LC325066 & LC325034 \\
\hline KS.KN 47882 & Finland, Asikkala & LC314641 & LC324968 & LC325067 & LC325035 \\
\hline KS.KN 47906 & Finland, Pernaja & LC314642 & LC324969 & - & LC325036 \\
\hline KS.KN 47907 & Finland, Porvoo & LC314643 & LC324970 & LC325068 & LC325037 \\
\hline KS.KN 48312 & Finland, Heinävesi & LC314644 & LC324971 & - & LC325038 \\
\hline KS.KN 48372 & Finland, Kuhmo & LC314645 & LC324972 & - & LC325039 \\
\hline
\end{tabular}

${ }^{a}$ Kurose et al. (1999).

${ }^{b}$ Kurose et al. (2005).

'Yamada and Masuda (2010).

addition, we employed published data from public databases, as specified in Tables 1 and S1.

\section{2 | DNA extraction, amplification, and sequencing}

Total DNA was extracted from the samples using the DNeasy Tissue \& Blood Kit (QIAGEN) or QIAamp DNA Investigator Kit (QIAGEN), following the manufacturer's protocols, including extraction blanks for the negative control. All experiments were done with filter tips and disposal tubes for preventing the contamination in the present study.
Two fragments of the mtDNA, CR (around 550 base-pairs, bp) and Cytb (1,140 bp), and one from the Y-chromosomal ZFY (687 bp) and one from autosomal ASIP gene (480 bp; intron and exon), were amplified by PCR with the primers shown in Table S2. For DNA degraded samples, we amplified small fragments (165-705 bp) overlapping each other. In the samples of dried skins, relatively shorter DNA fragments were amplified. Furthermore, we duplicated the experiments for the data confirmation on the degraded samples.

PCR was carried out in a volume of $10 \mu \mathrm{l}$ including $2.0 \mu \mathrm{l}$ of $5 \times$ Prime STAR GXL DNA Buffer (Takara), $0.8 \mu \mathrm{l}$ of dNTP mixture 
(2.5 mM each dNTP; Takara), $0.2 \mu$ of Prime STAR GXL DNA

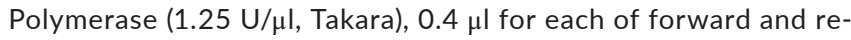
verse primers $(10 \mathrm{pmol} / \mu \mathrm{l}), 0.4$ of bovine serum albumin $(0.4 \mu \mathrm{g} / \mu \mathrm{l}$, Roche), and 1.0-2.0 $\mu$ l of the DNA extract, and the volume was adjusted to a total of $10 \mu \mathrm{l}$ with distilled water. The amplification was performed with $30-45$ cycles of $98^{\circ} \mathrm{C}$ for $10 \mathrm{~s}, 54-61.4^{\circ} \mathrm{C}$ for $15 \mathrm{~s}$, and $68^{\circ} \mathrm{C}$ for $1 \mathrm{~min}$ using the Thermal Cycler TP400 (Takara). To check the amplicon, $3 \mu$ l of the PCR product was electrophoresed on a $2 \%$ agarose gel, stained with ethidium bromide, and observed under an ultraviolet illumination. Then, the PCR products were purified with the QIAquick PCR Purification Kit (QIAGEN). In addition, we confirmed no PCR amplification in the negative controls.

The DNA cycle sequencing was performed with the BigDye v3.1 or 1.1 Cycle Sequencing Kit (Applied Biosystems, ABI), using the PCR primers shown in Table S2. Sequencing reaction was performed in a volume of $10 \mu \mathrm{l}$ containing $1.75 \mu \mathrm{l}$ of $5 \times$ BigDye Sequencing Buffer (ABI), $0.5 \mu \mathrm{l}$ of Ready Reaction Premix (ABI), $0.5 \mu \mathrm{l}$ for each of the primers, and $2.0 \mu \mathrm{l}$ of DNA template, and the volume was adjusted to $10 \mu \mathrm{l}$ with distilled water. Cycle sequencing was performed with a preheating at $96^{\circ} \mathrm{C}$ for $1 \mathrm{~min}$ and 25 cycles of $96^{\circ} \mathrm{C}$ for $10 \mathrm{~s}, 50^{\circ} \mathrm{C}$ or $55^{\circ} \mathrm{C}$ for $5 \mathrm{~s}$, and $60^{\circ} \mathrm{C}$ for $4 \mathrm{~min}$. The cycle PCR products were precipitated with ethanol, and dissolved in $10 \mu \mathrm{l}$ of formamide, and applied to an ABI 3,730 DNA Analyzer for sequencing. The sequence alignment for all loci was performed using MUSCLE in MEGA6 (Tamura, Stecher, Peterson, Filipski, \& Kumar, 2013).

\section{3 | Phylogenetic trees and networks}

The nucleotide substitution models for analyses of all loci were selected using the Bayesian information criterion (BIC) with PartitionFinder v1.1.1 (Lanfear, Calcott, Ho, \& Guindon, 2012). The selected models were used to reconstruct phylogenetic trees (gene genealogies) with two approaches and programs: MrBayes v3.2.6 (Ronquist et al., 2012) for analyses under Bayesian inference (BI) and Garli v2.01 (Bazinet, Zwickl, \& Cummings, 2014) for Heuristic maximum-likelihood analyses (ML). For analysis of the concatenated $C R$ and $C y t b$ sequence segments, separate substitution models were estimated for the $C R$ segment and for each of three codon positions in the Cytb (1,2,3): These were K81uf + I + G, K80 + G, HKY, and $\operatorname{TrN}+\mathrm{G}$, but in the phylogenetic analysis HKY and GTR models were used instead of K81uf and $\operatorname{TrN}$ models, respectively, because these models were not implemented in MrBayes (Hasegawa, Kishino, \& Yano, 1985; Kimura, 1980, 1981; Lanave, Preparata, Saccone, \& Serio, 1984; Tamura \& Nei, 1993). The list of the other nucleotide substitution models is shown in Table S3.

For the $\mathrm{BI}$ trees, Markov chain Monte Carlo (MCMC) analyses were run for $5 \times 10^{6}$ to $1 \times 10^{7}$ generations with trees sampled every 1,000 generations, and the first $25 \%$ of the trees were discarded as burn-in. The convergence of MCMC analyses was confirmed by indicating the average standard deviation of split frequencies was below $<0.01$, and the parameter values sampled from MCMC runs were checked in Tracer ver. 1.6 (http://tree.bio. ed.ac.uk/software/tracer/). The Bayesian posterior probabilities
(PP) were also obtained from MrBayes. In the reconstruction of the $M L$ trees, the effort to search for the best tree was repeated 20 times independently and terminated at 20,000 generations with Garli. The maximum-likelihood bootstrap percentages (BP) were obtained from 1,000 pseudoreplicates with Garli to assess the confidence values of tree nodes.

Two confidence values (PP and BP) for the reconstructed nodes were mapped on the trees using SumTrees 3.3.1 of the DendroPy package (Sukumaran \& Holder, 2010). Nodes of the trees were regarded as well supported when their PP was $\geq 0.95$ and BP was $\geq 70 \%$. Haplotypes from other three closely related species (Mustela nudipes Desmarest, 1822: AB601587 for CR, AB285332 for Cytb; M. kathiah Hodgson, 1835: AB601575, AB285331; M. erminea L., 1758: $A B 006730, A B 026101)$ were used as outgroups in the mtDNA tree. The M. erminea sequences of ZFY and ASIP (AB491595 and JX130732, respectively) were used as the references for these genes. The SINEs (short interspersed nuclear elements) region of the M. erminea's ZFY sequence was excluded in the analysis. These phylogenetic trees were visualized and edited with FigTree v1.4.2 (http://tree.bio.ed.ac.uk/software/figtree/).

Median-joining networks of the concatenated mtDNA $C R$ and Cytb, of ZFY, and of ASIP separately were reconstructed with POPART 1.7 (Leigh \& Bryant, 2015). The program PHASE implemented in DnaSP v5 (Librado \& Rozas, 2009) was used to estimate the haplotypes of ASIP. In all network analysis, the gap sites were treated as missing.

\section{4 | Divergence time and demographic history}

Population divergence times were estimated from the concatenated mtDNA two-locus data set using BEAST v2.4.8 (Bouckaert et al., 2014) package, with the outgroups mentioned above. Three calibration points were set on the basis of the divergence times among outgroup species and least weasels. Following Sato et al. (2012) and Kinoshita et al. (2015), a normal distribution with a mean of following time and $S D$ was adopted to this analysis: $5.985 \pm 0.315$ million years ago (mya) between $M$. nudipes and the others, $5.365 \pm 0.195$ mya between $M$. kathiah and the others except $M$. nudipes, and $3.685 \pm 0.285$ mya between M. erminea and M. nivalis. In addition, the published estimate of least weasel mtDNA Cytb substitution rate of 2.1\% $\mathrm{Myr}^{-1}$ from Dawson, Hope, Talbot, and Cook (2014) and the strict clock model were also used. The tree prior was set as the coalescent constant population model. The HKY + I + G substitution model was used for all loci, which was the best model for our data without partitions using BIC produced by PartitionFinder. The evolutionary rates of other loci were estimated based on these configurations. The MCMC analyses were run $1 \times 10^{8}$ generations with trees sampled every 1,000 generations, and the first $10 \%$ of the trees were discarded as burn-in. The effective sample sizes were confirmed by Tracer, with the requirements of convergence of MCMC chains and values for all parameters exceeding 200. The maximum clade credibility tree was selected using TreeAnnotator and visualized with FigTree. 


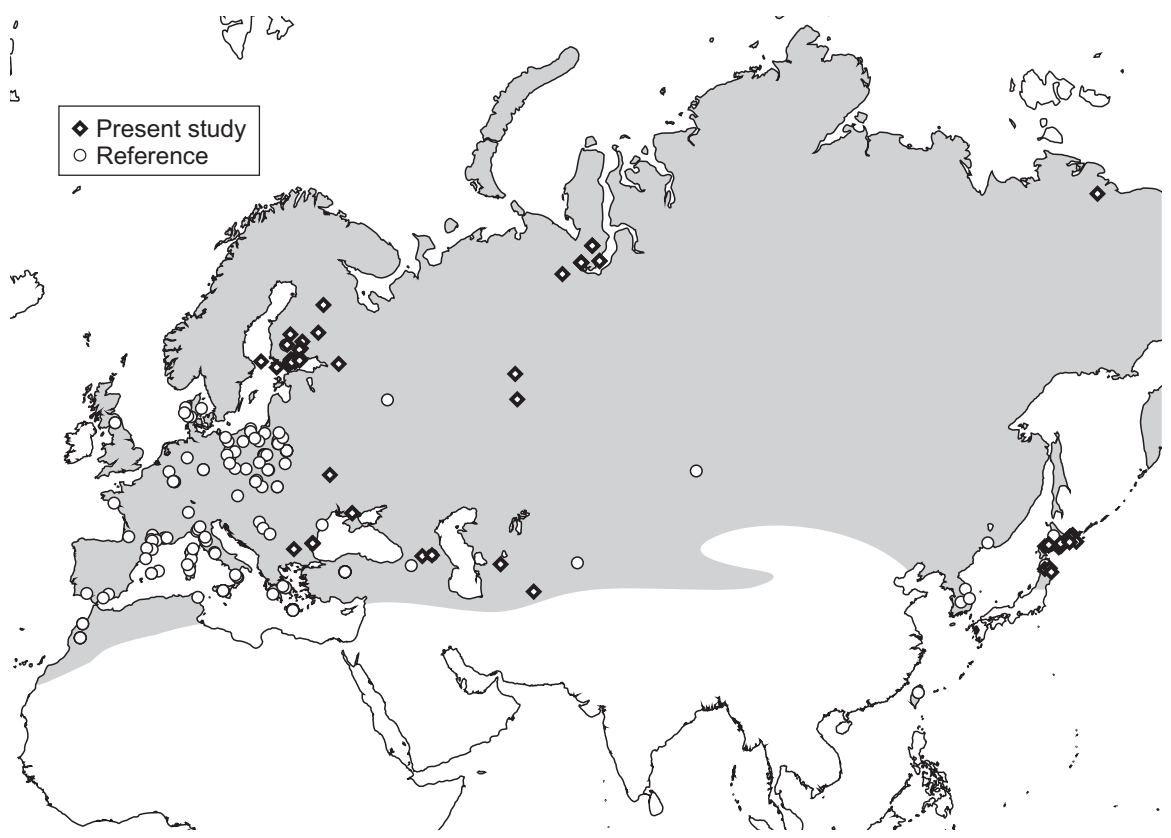

FIGURE 1 Sampling locations. The samples examined in the present study are shown as diamonds, and the detailed localities are shown in Table 1. According to the previous studies (Hosoda et al., 2000, 2011; Kurose, Abramov, \& Masuda, 2000; Kurose et al., 2005, 1999; Lebarbenchon et al., 2010; Lebarbenchon, Poitevin, \& Montgelard, 2006; Mcdevitt et al., 2012; Rodrigues et al., 2016), the reference localities are shown as circles and the detailed localities were indicated in Table S1. If the samples did not have detailed sampling localities in the previous studies, their plots were located at the metropolis of each country or prefecture. The gray color means the distribution range of least weasel in the Palearctic, modified from McDonald et al. (2016)

Demographic changes (effective population size history) were simulated by the Extended Bayesian Skyline Plot (EBSP) approached in BEAST. The HKY + I + G model and the substitution rate of $2.1 \% \mathrm{Myr}^{-1}$ for the mtDNA Cytb of the least weasel were applied to each of the two identified main mitochondrial clades separately (Clades I and II; 106 and 56 individuals, respectively). The MCMC analyzes were run $1 \times 10^{8}$ generations with trees sampled every 1,000 generations, and the first $10 \%$ of the trees were discarded as burn-in. The effective sample sizes and the convergence of MCMC chains were confirmed by Tracer.

\subsection{Genetic structure}

Genetic diversity and demographic history were estimated from each data set separately (i.e., concatenated mtDNA CR and Cytb, ZFY, and ASIP) with Arlequin ver. 3.5.1.3 (Excoffier \& Lischer, 2010), calculating the haplotype diversity, the nucleotide diversity, the neutrality tests of Tajima's D (Tajima, 1989), and Fu's $F_{s}$ (Fu, 1997).

Population structure was also assessed with SAMOVA (spatial analyses of molecular variance; Dupanloup, Schneider, \& Excoffier, 2002) implemented in SPADS 1.0 (Dellicour \& Mardulyn, 2014), using all 168 concatenated mtDNA CR and Cytb sequences. Specimens were grouped as populations by country, except for Japan where Hokkaido and Honshu were treated as different populations because there is a chromosomal difference between them. The number of a priori groups $(K)$ was varied between 2 and 10, with 10,000 iterations and 10 repetitions. Following Magri et al. (2006), the preferred $K$ was selected by choosing the highest $F_{\mathrm{CT}}$, and then, configurations with single-population groups were excluded. In addition, the pairwise differences among populations were estimated using the fixation index $\Phi_{\text {st }}$ (Excoffier, Smouse, \& Quattro, 1992).

\section{3 | RESULTS}

\section{1 | DNA sequencing}

A total of 210 novel sequences ( 45 for $C R, 69$ for $C y t b, 29$ for ZFY and 67 for ASIP) were obtained in the present study and deposited to the DDBJ database with accession numbers: CR, LC314601-LC314645; Cytb, LC324904-LC324972; ZFY, LC325040-LC325068; and ASIP, LC324973-LC325039 (Table 1). In the alignments, the novel sequences were compared with the previously reported data (Tables 1 and S1), and then, overlapped regions were used to classify the haplotypes. All haplotype numbers were shown in Tables 2 and S1.

\subsection{Diversity and genealogy of mtdna}

In all, 92 distinct haplotypes were identified from the 215 sequences of the mtDNA $C R$. The length of $C R$ was 514 bp including insertdeletion sites. The $\mathrm{BI}$ tree of $C R$ was multifurcate and unstructured with no clear clusters except for the Hokkaido population (Cluster le; Figure S1 and Alignment S1). Likewise, 116 haplotypes of Cytb were detected from 221 sequences of 1,117 bp. The BI tree of Cytb was also poorly resolved, but some populations including the Hokkaido population and some European populations made up regional clusters (Figure S2 and Alignment S2). 
TABLE 2 Haplotype numbers of samples examined in this study

\begin{tabular}{|c|c|c|c|c|c|c|c|c|c|c|}
\hline Voucher No. & \multicolumn{9}{|c|}{ Haplotype Nos. } & ALL \\
\hline Mn4 & A16 & B53 & $\mathrm{C} 63$ & D1 & E9 & E9 & F17 & G40 & $\mathrm{H} 2$ & 119 \\
\hline Mn5 & A16 & B23 & $\mathrm{C} 22$ & - & E9 & E9 & - & $\mathrm{G} 2$ & - & - \\
\hline Mn6 & A33 & B23 & C53 & - & E9 & E9 & - & G31 & - & - \\
\hline NEM01 & A33 & B23 & C53 & - & E9 & E9 & - & G31 & - & - \\
\hline OBH01 & A30 & B23 & C38 & - & E9 & E9 & - & G12 & - & - \\
\hline S12 & A17 & B24 & $\mathrm{C} 23$ & D1 & E9 & E9 & $\mathrm{F} 2$ & G3 & $\mathrm{H} 2$ & 12 \\
\hline S13 & A16 & - & - & - & E9 & E9 & - & - & - & - \\
\hline OB2 & A16 & B38 & C39 & - & E9 & E9 & - & G13 & $\mathrm{H} 11$ & - \\
\hline HIT1 & A34 & B23 & C54 & - & E1 & E9 & - & G33 & $\mathrm{H} 11$ & - \\
\hline HIT2 & A30 & B23 & C38 & D1 & E1 & E9 & F19 & G12 & $\mathrm{H} 4$ & 120 \\
\hline N26 & A37 & B23 & C58 & D1 & E6 & E6 & F14 & G39 & $\mathrm{H} 8$ & 118 \\
\hline N27 & A36 & B23 & C57 & D1 & E6 & E6 & F16 & G38 & $\mathrm{H} 8$ & 117 \\
\hline N28 & A36 & B23 & C57 & - & E6 & E6 & - & G38 & $\mathrm{H} 11$ & - \\
\hline N29 & A36 & B23 & C57 & - & E6 & E6 & - & G38 & $\mathrm{H} 11$ & - \\
\hline N30 & A35 & B23 & C55 & - & E6 & E6 & - & G37 & $\mathrm{H} 11$ & - \\
\hline N31 & $\mathrm{A} 2$ & B48 & C56 & D1 & E9 & E6 & F15 & G36 & $\mathrm{H} 3$ & 116 \\
\hline IWA1 & A45 & B59 & $\mathrm{C} 66$ & D1 & E5 & E5 & F18 & G41 & $\mathrm{H} 12$ & 127 \\
\hline IWA2 & A45 & B59 & $\mathrm{C} 66$ & D1 & E5 & E5 & F18 & G41 & $\mathrm{H} 12$ & 127 \\
\hline 151646 & $\mathrm{~A} 27$ & B88 & C118 & - & E1 & E2 & - & G52 & - & - \\
\hline 278252 & A43 & B87 & C115 & - & E2 & E2 & - & G51 & - & - \\
\hline 79252 & A77 & B86 & C109 & - & - & - & - & - & - & - \\
\hline 79253 & A79 & - & - & - & - & - & - & - & - & - \\
\hline 79254 & A80 & - & - & - & - & - & - & - & - & - \\
\hline 79255 & A76 & B85 & C108 & - & E3 & E3 & - & G50 & - & - \\
\hline 79271 & A75 & B84 & C107 & D1 & - & - & F26 & - & - & - \\
\hline 79272 & A81 & - & - & - & - & - & - & - & - & - \\
\hline 79273 & A82 & - & - & - & - & - & - & - & - & - \\
\hline 79274 & A83 & - & - & - & - & - & - & - & - & - \\
\hline 79304 & A74 & B83 & C106 & - & E2 & E2 & - & G49 & - & - \\
\hline 79307 & A73 & B82 & C105 & - & E4 & E4 & - & G48 & - & - \\
\hline RLEN3 & A18 & B27 & $\mathrm{C} 27$ & D1 & E2 & E2 & F3 & G6 & $\mathrm{H} 5$ & 13 \\
\hline RIND1 & A21 & B30 & C29 & - & E1 & E1 & - & G8 & - & - \\
\hline ROMS1 & A74 & - & - & - & - & - & - & - & - & - \\
\hline
\end{tabular}


TABLE 2 (Continued)

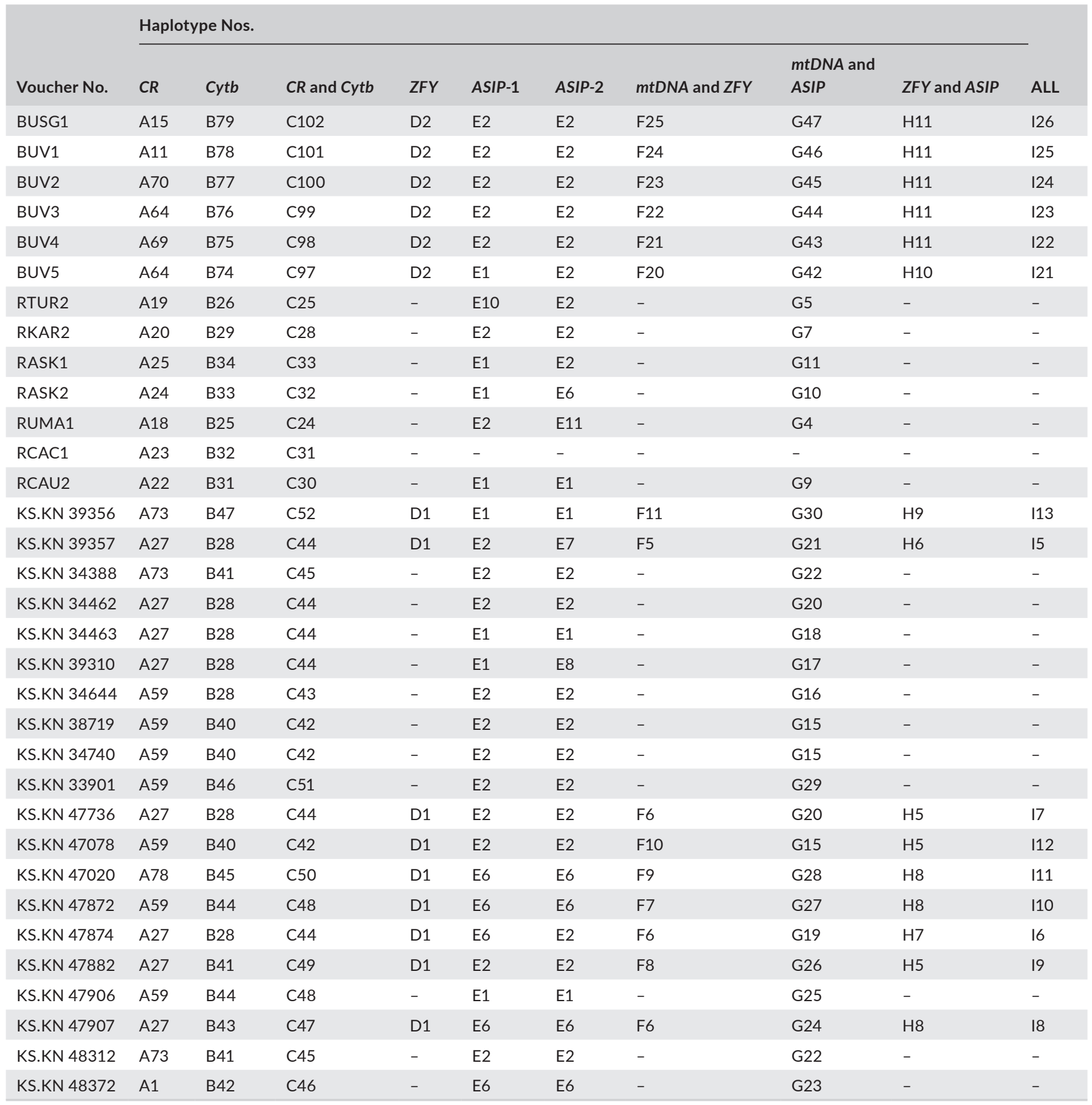

In the concatenated $C R$ and Cytb data (1,631 bp), 119 distinct haplotypes were recognized among 168 individuals (69 newly sequenced). This $\mathrm{BI}$ tree exposed two main clades (Figure 2 and Alignment S3), corresponding to the Clades I and II of Lebarbenchon et al. (2010); however, the support values were lower than the previous report. Clade I was in low monophyly with low supported values
(0.77 PP and 9\% BP), while Clade II had relatively high values (1.0 PP and 50\% BP; cf, 1.0/ 93\% for Clade I and 0.94 / 76\% for Clade II in Lebarbenchon et al., 2010; Figure 2). All samples were divided to Clades I, II, and the others, based on the topology of this BI tree (Figure 2). The others consisted of the individuals of Turkmenistan (C25 and C28), Georgia (C30 and C31), and Ukraine (C32 and C33).

FIG URE 2 A Bayesian phylogenetic tree of concatenated mtDNA CR and Cytb. Posterior probabilities and maximum-likelihood bootstrap values are shown on nodes. Haplotype names are coincided with Tables 2, S1, and Figure 4. The novel haplotypes are shown with bold. The cluster names are given at the terminal branches. The symbols and colors are corresponding to Figure 3. These cluster-supporting values are shown by bold and italic. The distribution and coalescent time are also indicated. The $\mathrm{x}$ marks indicate the individuals from the Black SeaCaspian Sea region 


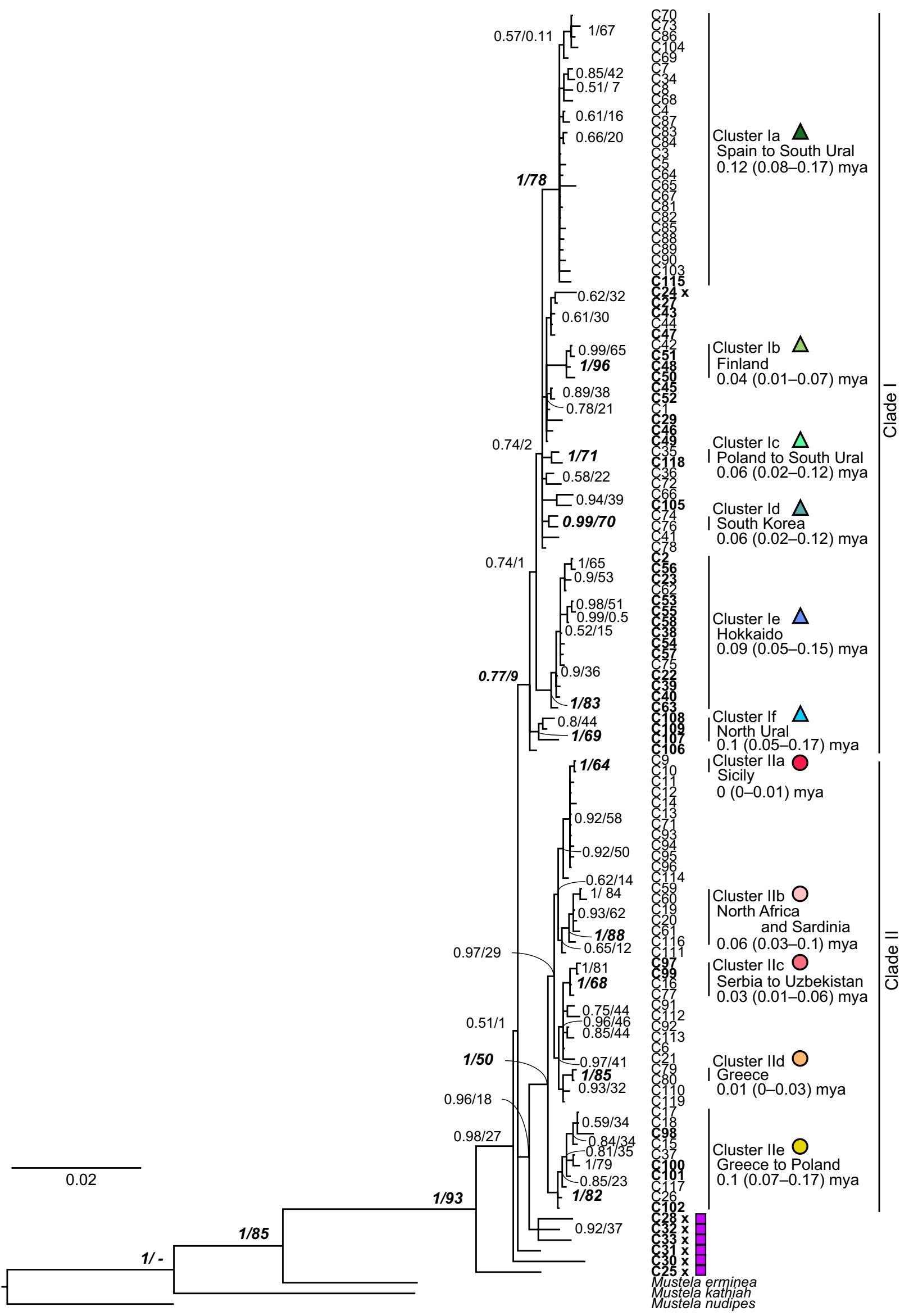


These individuals were located at the most basal position. The ML tree in turn was multifurcated and did not have the main clades (Figure S3).

The $C R$ and $C y t b$ concatenated $\mathrm{BI}$ tree also exhibited eight clusters with high support values (Figure 2). Cluster la consisted of individuals from Spain to South Ural. Cluster lb was shared by individuals from Finland. Cluster Ic distributed in Poland and South Ural. Cluster le consisted by only the Hokkaido population. Cluster If included only the North Ural individuals. Cluster Ilb was shared by North African individuals and Sardinia. Cluster Ild consisted of individuals from Greece, only. Cluster Ile was found from Greece to Poland. In addition, there were three clusters with relatively high support values: Cluster Id was consisted of South Korea, Cluster Ila was shared by Italian and its insular individuals, and Cluster IIc was distributed in Serbia, Bulgaria, and Uzbekistan. Individuals of Honshu Island of Japan shared haplotype C66, which is more closely related to that $\mathrm{C} 105$ of a North Ural individual than the Hokkaido population. The locations of clades and clusters were plotted on a Palearctic map (Figure 3).

The mtDNA haplotype network indicated two main clades clearly, compared to the $\mathrm{BI}$ tree (Figure 4 and Alignment S4). Clade
I was too complicated to read the phylogeographical relationships between haplotypes with many loops indicating the homoplasies. In contrast, Clade II had relatively clear internal structure and the mentioned clusters were supported. Haplotype C28 from Turkmenistan and the Ukrainian C32 and C33 were not placed in either of the two main clades but occupied an intermediate position of them.

\subsection{Diversity in the paternal and biparental genes}

Only two ZFY haplotypes, D1 and D2, were found from among 30 individuals, of which 29 were newly sequenced in this study. These two haplotypes were strongly diverged, with eight nucleotide differences and an 8-bp indel between them (Figure 5 and Alignment S5). D1 was shared by 12 individuals of Japan (Hokkaido and Honshu), two of Russia and nine of Finland, whereas D2 was common to all six individuals of Bulgaria. The Bulgarian D2 featured the 8-bp insertion, which was also present in the ZFY sequence of the closely related Mustela erminea (the stoat).

For ASIP, 12 haplotypes were detected from 67 individuals obtained in the present study (Figure 5 and Alignment S6), which had 12 polymorphic sites. A central haplotype $\mathrm{E} 1$ was found in all regions

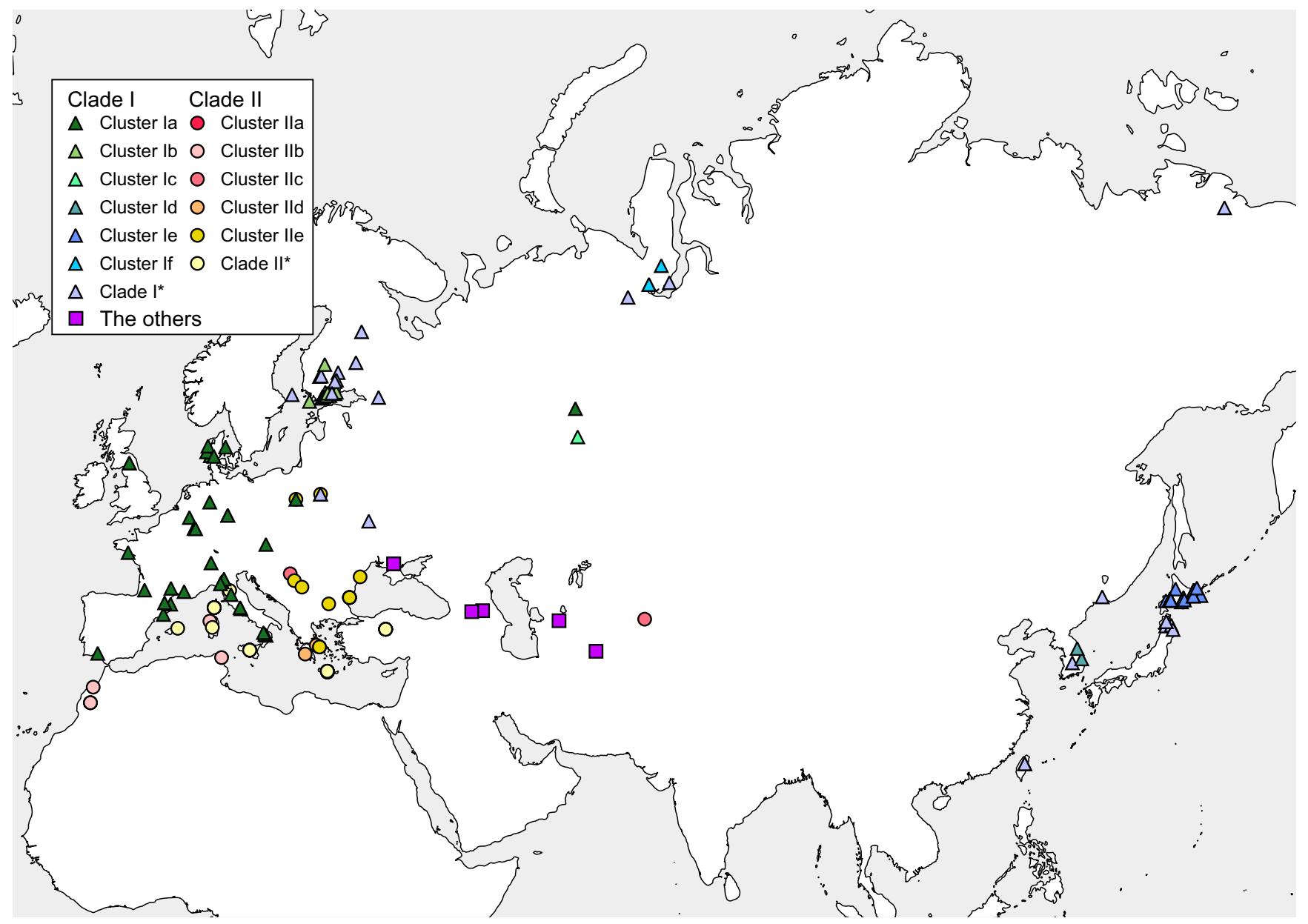

FIGURE 3 Locations of clades and clusters in the Palearctic region. The clade and cluster locations are shown by symbols and colors. Information on localities is the same as Figure 1. The asterisks mean the haplotypes were not grouped to any clusters but included to each clade. The purple means the other haplotypes, which were not included in any clades in Figure 2 


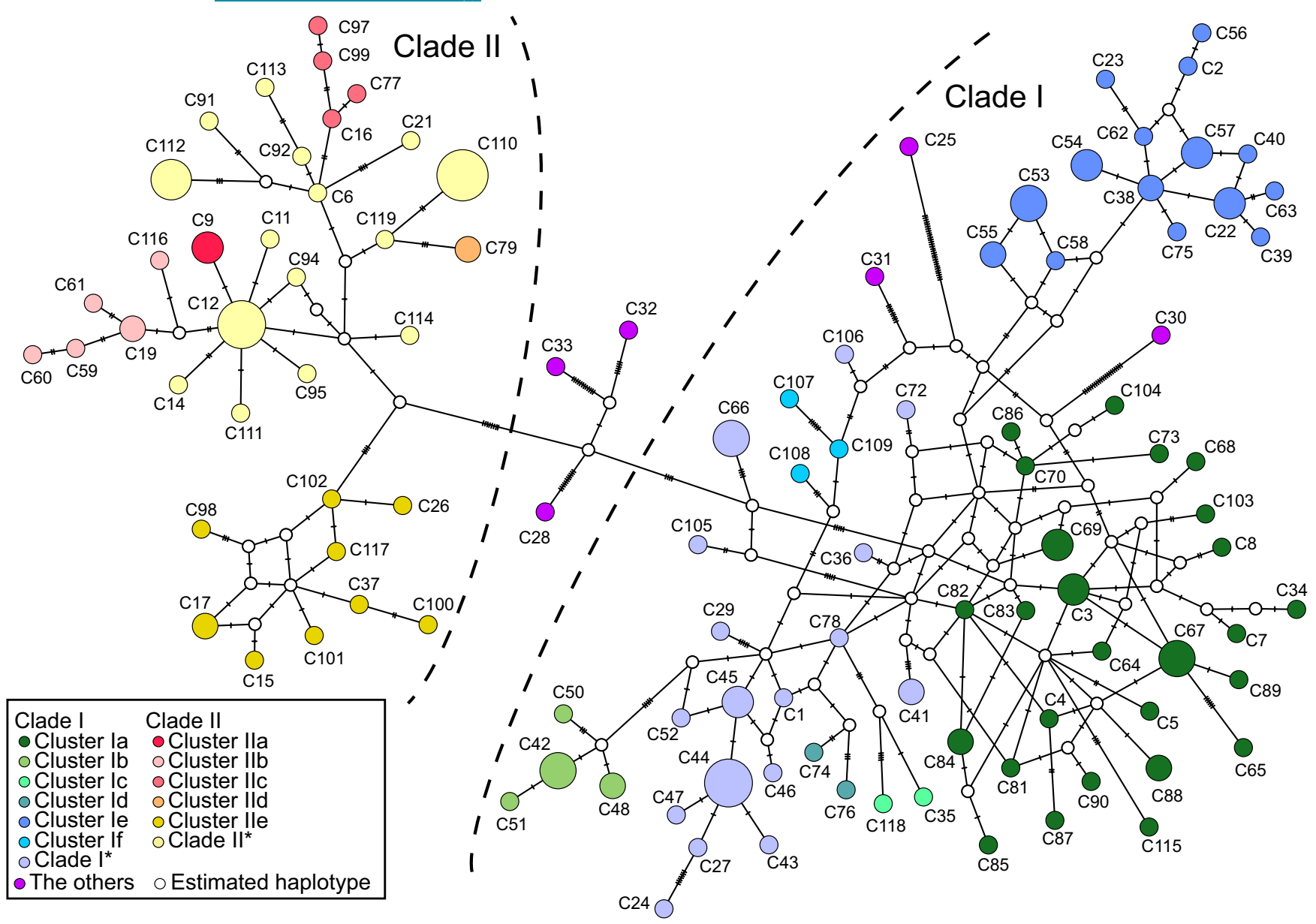

FIGURE 4 A haplotype network of concatenated mtDNA CR and Cytb. The sizes of circles indicate the proportion of haplotype frequencies. Open circles are estimated haplotypes, and a hatch mark between haplotypes means a nucleotide substitution. Haplotype names are the same as in Figure 2 and Tables 2, S1. The colors are coincided with Figure 3. All samples were divided into each clade or the others, based on Figure 2. The asterisks mean the haplotypes were not grouped to any clusters but included to each clade. The purple circles mean the other haplotypes, which were not included in any clades in Figure 2. If nucleotide sequences of the haplotypes differ by only indels or unresolved nucleotides, they were treated as the same haplotypes in the POPART analysis: C9 and C10; C12, C13, C71, C93 and C96; C17 and C18; C19 and C20; C45 and C49; and C79 and C80

except Honshu, where all individuals shared another haplotype E5. Hokkaido in turn had five haplotypes. However, no further phylogeographical structure was seen, and the differences between haplotypes were just one or two substitutions.

\subsection{Phylogenetic trees from multilocus data}

All sequence data on the four loci (mtDNA CR, mtDNA Cytb, ZFY, and $A S I P$ ) obtained in the present study were concatenated to reconstruct a $\mathrm{BI}$ tree (Figure S4a and Alignment S7). This tree consisted of 29 individuals of $2,823 \mathrm{bp}$ with the stoat (Mustela erminea) as an outgroup, and the two main clades were supported with higher bootstrap values compared to the mtDNA tree: $92 \%$ for Clade I and 98\% for Clade II. On the other hands, if ZFY was excluded from the data set, no strongly supported major clustering was seen, except for some regional clusters such as Finland, Hokkaido, and Bulgaria (Figure S4 and Alignments S7-S10).

\subsection{Divergence time and population expansion history}

The Bayesian phylogram with BEAST analyses, based on the two concatenated mtDNA loci, had a topology similar to that from MrBayes (Figure S5). The time of most recent common ancestor (tMRCA) of the least weasels would have been on 740 (560-940, 95\%HPD) thousand years before present (kyBP), at the split of the Turkmenistan lineage (C25) from the others. The coalescence of the remaining lineages would have been 480 (370-600) kyBP. The divergence time of the two main clades could not be traced from this tree, caused by the low PP support $(<0.95)$. The tMRCA of Clade II was 200 (140-270) kyBP. The divergence times of the clusters were also obtained (Figure 2). Based on the demographic fluctuation analysis, both Clades I and II had experienced the population expansion from small populations. Clade II was relatively stable, whereas the expansion of Clade I was more rapid. (Figure 6, and Alignments S11 and S12). 
FIGURE 5 Haplotype networks of ZFY (a) and ASIP (b). The sizes of circles indicate the proportion of haplotype frequencies. Open circles are estimated haplotypes, and a hatch mark between haplotypes means a nucleotide substitution. The haplotype names are the same as Table 2. Individuals from each region are distinguished by using different colors: Hokkaido, orange; Honshu, red; Russia, green; Ural, yellow; Bulgaria, gray; Turkmenistan, purple; Ukraine, light green; Georgia, sky blue; and Finland, light brown
ZFY

Hokkaido

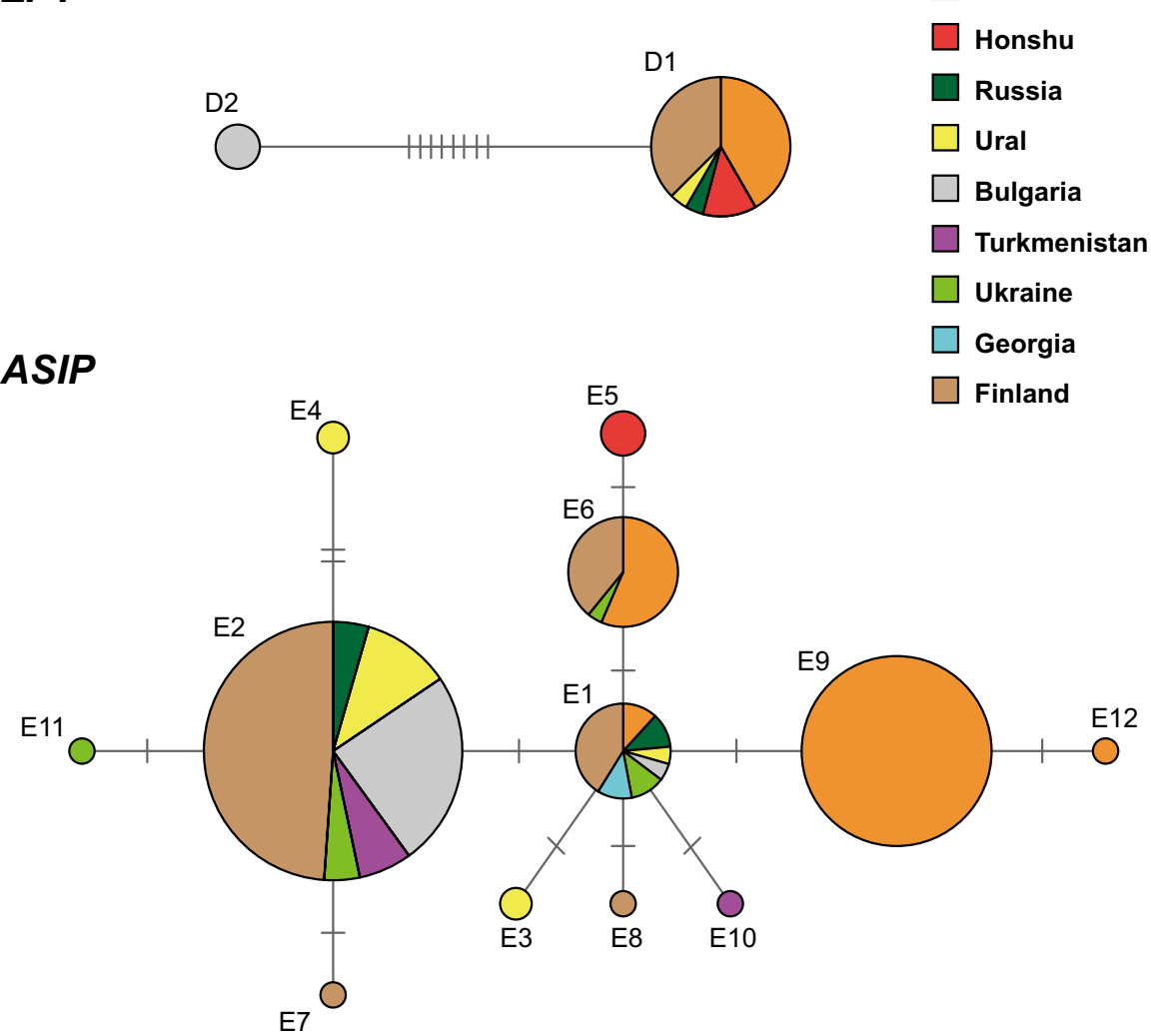

\subsection{Genetic structure}

A hierarchical partition of genetic diversity in the concatenated mtDNA CR and Cytb data by region, and by clade and intra-clade clusters, is shown in Table 3. Overall, the nucleotide diversities were low (shallow genealogy) but haplotype diversities were high. Populations of the Black Sea-Caspian Sea region had the highest nucleotide diversities (0.028 for Turkmenistan; 0.025 for Ukraine; and 0.026 for Georgia), and that of the Ural population (0.009) was also relatively high. Cluster If had the highest nucleotide diversity among clusters. The Honshu population in turn was monomorphic at all loci. Significant values of Tajima's $D$ and Fu's $F_{s}$ statistics are suggestive of the rapid expansion in the Palearctic population. Likewise, treating the mitochondrial lineages separately, Clade I and Cluster la show signatures of rapid expansion. The Hokkaido population, Clade II and Cluster Ile, also had significant values of
FIGURE 6 Extended Bayesian skyline plots using concatenated mtDNA $C R$ and Cytb of the least weasels (Clades I and II). Two lines show the range of $95 \%$ central posterior density (CPD), and the broken line indicates the median. Plots indicate the population expansion

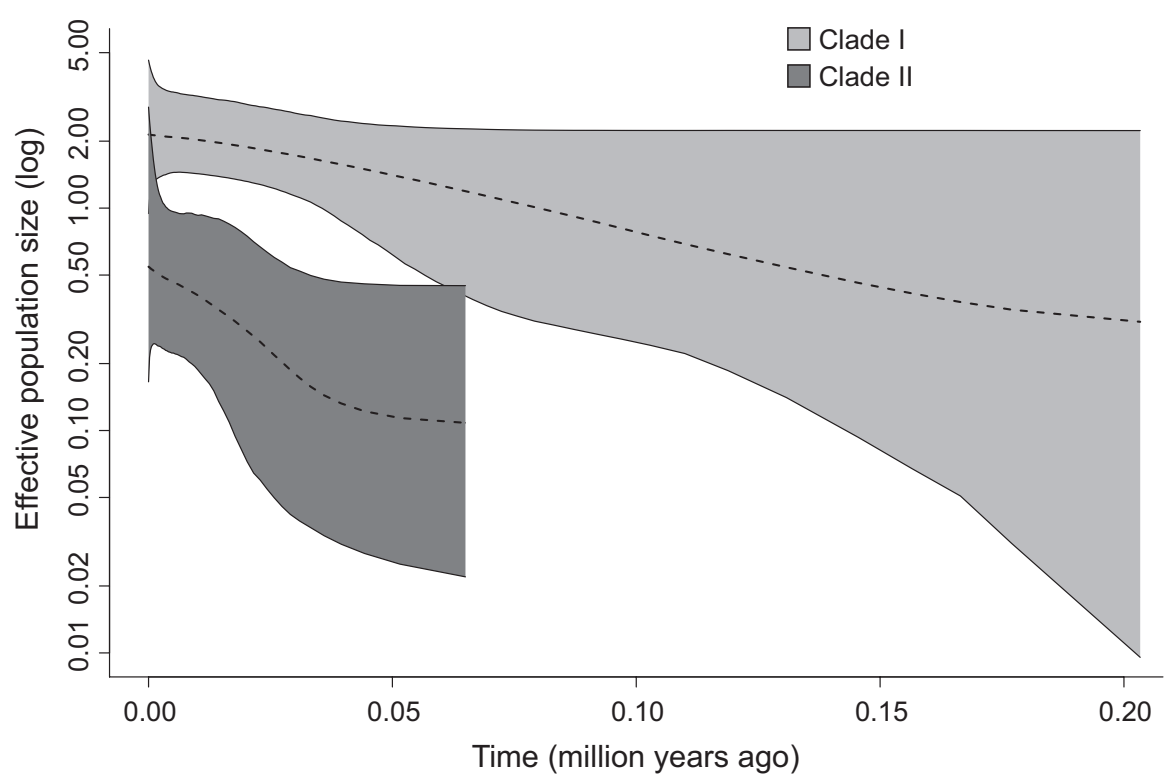


TAB LE 3 Statistical data of the least weasel in Palearctic

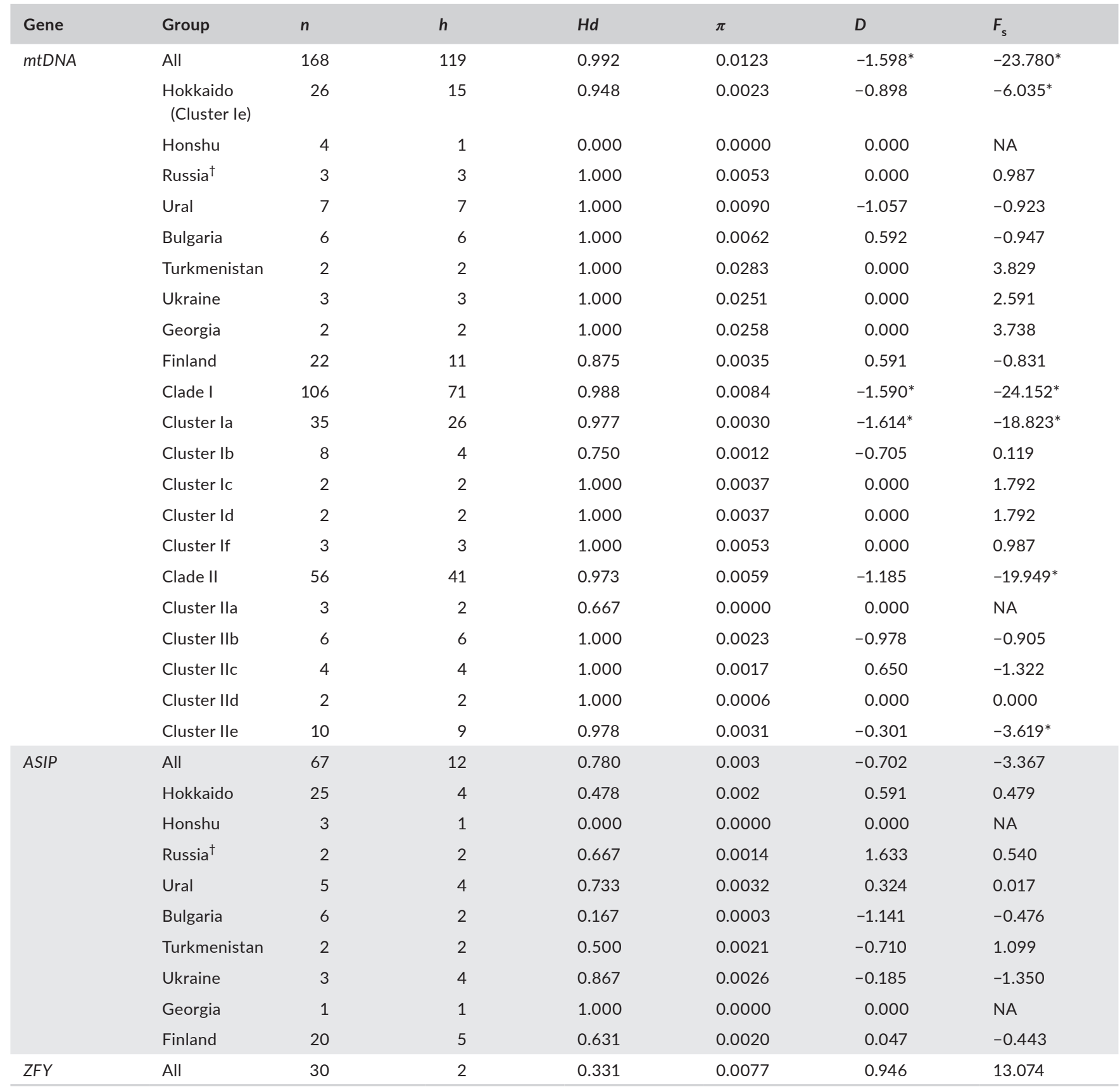

Note: Asterisks show that values of $D$ or $F_{s}$ are statistically significant $(p<.05)$. A dagger means excluded the Ural individuals.

Abbreviations: $D$, Tajima's $D$; $F_{s}$, Fu's $F_{s}$; $h$, number of haplotypes; $H d$, haplotype diversity; n, number of individuals; NA, not analysis; $\pi$, nucleotide diversity.

Fu's $F_{s}$. The autosomal ASIP showed an overall low nucleotide diversity (0.003) and a high haplotype diversity (0.78). The Y-chromosomal ZFY showed relatively low nucleotide and haplotype diversities (0.008 and 0.331). The data of ZFY and ASIP did not indicate an expansion.

Least weasels had genetic differences to each other $\left(\Phi_{\text {st }}=0.556\right)$ in the Palearctic, but an attempt to divide the regional populations to subgroups by SAMOVA was not very successful with Alignment S4. A search for the number of independent groups $(K)$ that show the maximum inter-group diversity $F_{C T}$ showed that this statistic increased with $K$ and did not reach a plateau over $K=10$ (Figure S6). A configuration of $K=3$, for which $F_{C T}$ (0.368) was the highest among the others without single-population groups, was very similar to the mtDNA haplotype network (Figure 3). Group I represented populations distributed across the continent from Spain to Japan, which carry the mtDNA Clade I except for Georgia. Group II in turn included populations of Romania, Serbia, Bulgaria, Greece, Turkey, Tunisia, and Morocco, which harbor mtDNA Clade II. Group III was composed of the populations from Turkmenistan and Ukraine (Table 4). 
TAB LE 4 Population grouping of the least weasels in Palearctic by SAMOVA

\begin{tabular}{|c|c|c|c|c|c|c|c|c|c|}
\hline & \multicolumn{9}{|l|}{$K$} \\
\hline Hokkaido & I & I & I & I & I & I & I & I & I \\
\hline Honshu & I & I & II & II & II & II & II & II & II \\
\hline Russia & I & I & 1 & II & II & III & III & III & III \\
\hline Bulgaria & II & II & III & III & III & IV & IV & IV & IV \\
\hline Ukraine & 1 & III & I & IV & IV & V & V & V & V \\
\hline Georgia & I & I & I & II & II & III & V & V & VI \\
\hline Finland & I & I & 1 & II & II & III & III & III & III \\
\hline France & I & I & I & V & V & $\mathrm{VI}$ & VI & VI & VII \\
\hline Switzerland & I & I & 1 & V & VI & VII & VII & VII & VIII \\
\hline Romania & II & II & III & III & III & IV & IV & IV & IV \\
\hline Greece & II & II & III & III & III & IV & VIII & IX & $x$ \\
\hline United Kingdom & I & I & I & V & VI & VII & VII & VII & VIII \\
\hline Poland & I & I & I & V & V & VI & VI & VI & VII \\
\hline Spain & I & I & I & V & V & VI & VI & VI & VII \\
\hline Belgium & I & I & 1 & V & VI & VII & VII & VII & VIII \\
\hline Germany & 1 & I & 1 & V & VI & VII & VII & VII & VIII \\
\hline Serbia & II & II & III & III & III & IV & IV & IV & IV \\
\hline Turkey & II & II & III & III & III & IV & VIII & IX & $x$ \\
\hline$F_{C T}$ & 0.3410 & 0.3685 & 0.3563 & 0.4010 & 0.4282 & 0.4722 & 0.4702 & 0.4849 & 0.5092 \\
\hline$F_{S T}$ & 0.6510 & 0.6507 & 0.6461 & 0.5890 & 0.5820 & 0.5821 & 0.5762 & 0.5751 & 0.5764 \\
\hline$F_{\mathrm{SC}}$ & 0.4704 & 0.4470 & 0.4502 & 0.3138 & 0.2690 & 0.2083 & 0.2002 & 0.1750 & 0.1368 \\
\hline
\end{tabular}

Note: $K$ is the number of groups.

\section{4 | DISCUSSION}

\subsection{Phylogeography of the least weasel in Palearctic}

Our data from the concatenated mtDNA CR and Cytb sequences from a geographically expanded data set demonstrate a confused phylogeographic structure of the least weasels in Palearctic. The tree topologies agree with the two main lineages (Clades I and II) of Lebarbenchon et al. (2010), whereas the support values could not provide full confidence on Clade I's monophyly (Figure 2). Clade I has a broad distribution across northern Palearctic, from Spain in the west to Japan in the east, while Clade II is limited to the South western part of the Palearctic, between North Africa and East Europe. At a lower level, the least weasels were tentatively classified into eleven mtDNA clusters. The Turkmenistan lineage of Central Asia plausibly represents the most ancestral split among all Palearctic populations, as in the data of Kurose et al. (2005).

Our data expanded the coverage of European sampling, for example, Bulgaria and the Urals, supplementing the data of Lebarbenchon et al. (2010) and Rodrigues et al. (2016, 2017). The Bulgarian population was separated into two Clusters (IIc and Ile), and the Northern Urals population consisted of one distinctive Cluster (If) by itself. Individuals from around the Black and Caspian Seas had the new Cytb haplotypes that seemed to represent the most ancestral lineages branches of the genealogy (Figure 2). 
Furthermore, the Turkmenistan and Ukraine haplotypes appeared at an intermediate position between Clades I and II in the mtDNA haplotype network (Figure 4). This configuration probably brings about the lower confidence values of the main clades, relative to those reported by Lebarbenchon et al. (2010) and McDevitt et al. (2012).

The SAMOVA analysis also suggests the ambiguity for the phylogeographic structure, although the interpopulation component of variation is large $\left(\Phi_{s t}=0.556\right)$. The data point to a history of demographic and geographic expansions that have taken place across large areas while more ancestral diversity has been retained in certain segments of the range. The nucleotide diversity through the Palearctic population is quite low (0.012), while the haplotype diversity is very high (0.992; Table 3 ). This suggests that the least weasels experienced a rapid demographic expansion from a small population, as also indicated by the Bayesian simulation, Tajima's $D$ and Fu's $F_{s}$ statistics (Figure 6 and Table 3). Remarkably, similar results were also reported in the closely related species stoat M. erminea (Dawson et al., 2014). The data showed low genetic differences and suggested a rapid expansion of $M$. erminea from Spain across the continent and through Beringia to North America. Such continent-wide expansions have also been inferred from other carnivorans, such as Red fox (Vulpes vulpes Linnaeus, 1758) and Brown bear (Ursus arctos Linnaeus, 1758; Korsten et al., 2009; Statham et al., 2014).

The phylogeographic structure also shows some phenotypic correlates. It seems that Clade II has survived and maintained a relatively constant population size and high genetic diversity in the temperate region in the south western part of the Palearctic, whereas the expansive Clade I represents adaptation to the cold regions. On the other hand, the SAMOVA grouping $(K=2)$ coincided with the distribution of the two coloration types recognized by Abramov and Baryshnikov (2000). Group I correlates with the nivalis-type coat color and Group II with the vulgaris type. Atmeh, Andruszkiewicz, and Zub (2018) demonstrated a clear relationship between the predation pressure and the camouflage of pelage coloration in a field experiment. One could speculate that this also affected the demographic and evolutionary histories. Clade I (Group I) expanded rapidly across Palearctic including the cold regions.

Our study also for the first time addressed the signals of population history in variation of a biparentally inherited gene ASIP and the paternally inherited ZFY. The ASIP haplotype network, however, did not have any phylogeographic variation (Figure 5). Even the Turkmenistan individual, which had a distinct mtDNA lineage, shared haplotype E2 widespread across the range, in Bulgaria, Urals, Russia, Finland, and Hokkaido. The ZFY haplotype network in turn had a distinct subdivision of two main lineages that corresponded with the mtDNA Clade I-II split (Figure 5). Haplotype D1 was distributed from Finland to Japan. This distribution pattern is indeed similar to that in the gray red-backed vole (Craseomys rufocanus Sundevall, 1846) which exhibits a monomorphism from western to far eastern Russia, within the partial sequence of the $Y$ chromosomal DNA (Abramson, Petrova, Dokuchaev, Obolenskaya, \& Lissovsky, 2012), and the spatial distribution of mtDNA and
Y-chromosomal DNA haplotypes was slightly different. Our spatial distribution of the haplotypes also differed by each gene. As one hypothesis, this discordance could be caused by behavioral differences between sexes of least weasels. The least weasel has the significant sexual dimorphism in body size (greater male vs. female) and sex-biased differences in habitat use (King \& Powell, 2007). Furthermore, McDevitt et al. (2013) suggested the dispersal of least weasels was sex-biased toward males. The male wide dispersal could be attributed to the phylogeographical status. In fact, the two main clades are supported with high values if the BI trees included ZFY sequences in data sets (Figure S4). Similar conclusions about discordant diversity in multiple loci from the same species have been drawn from other studies, such as Abramson et al. (2012) and Jones and Searle (2015). They also suggested that the discordant may have been caused by the sex biased dispersal in male and female voles and mice. If the male-biased dispersal of least weasels is true, it is easy to suppose that the large males had been strongly affected by cold temperature and could not distribute in high latitude, considering that Zub et al. (2011) suggested larger least weasel had low survival rate in cold environments.

\subsection{Characteristics of clusters and local populations}

We recognized some lower-level structure in the mtDNA genealogy of the least weasels, represented by eleven mtDNA clusters with relatively high support values (Figure 2). Three of these Clusters (Ib, Ic, and If) were newly recognized in the present study. Cluster If, only found in the Northern Urals, has the highest intra-cluster diversity. The tMRCA of this cluster was dated approximately 100 kyBP, close to MIS (marine isotope stage) 5c (105-93 kyBP, Räsänen, Huitti, Bhattarai, Harvey, \& Huttunen, 2015). The population might then represent a relict that survived the glacial period, and the Ural region would have been one of the cryptic refugia for the species. Actually, based on the paleontological study, Kosintsev, Gasilin, Gimranov, and Bachura (2016) reported the least weasel appeared consistently from MIS $5 \mathrm{e}$ in the Ural caves. Likewise, previous studies of other mammalian species also suggested possible refugia in the Ural Mountains. For example, the sables (Martes zibellina Linnaeus, 1758; Kinoshita et al., 2015) and the bank voles (Myodes glareolus Schreber, 1780; Deffontaine et al., 2005) from the Ural Mountains had relatively higher genetic diversities, suggesting the polymorphic status of relict populations of them. The Ural Mountains were reported as refugia for the common shrews (Sorex araneus Linnaeus, 1758) by Polyakov et al. (2001). Cluster Ib consisted of Finnish individuals, and Cluster Ic consisted of just two individuals from Poland and South Ural.

The remaining eight clusters were already reported previously (Kurose et al., 2005, 1999; Lebarbenchon et al., 2010; Rodrigues et al., 2016, 2017). Cluster la (=subclade la) is now shown to be distributed from Spain to South Urals, and its estimated tMRCA is projected twofold older than by Lebarbenchon et al. (2010) (120 kyBP vs. 62kyBP). Kurose et al. (1999), Kurose et al. (2005) first reported the Cluster le 
(Hokkaido). This tMRCA was estimated as less than 200 kyBP, but the present study showed around 90 kyBP. The result suggests that ancestors of the Hokkaido population could be prevented to pass the Tsugaru Strait, which separates Honshu and Hokkaido, because that strait was formed around 100-150 kyBP (Ohshima, 1991).

Remarkably, the Honshu population in Japan has no variation on any loci, and this lineage (C66) was more closely related to the North Ural lineage (C106) than the Hokkaido population in the mtDNA analysis. The ZFY haplotype D1, however, was shared among Honshu, Hokkaido, and North Ural. The number of chromosomes was also different between the Honshu population $(2 n=38)$ and the Hokkaido population $(2 n=42$; Obara, 1991). In addition, all studied populations from Eurasia and North America bear the karyotypes similar to that of the Hokkaido population (Mandahl \& Fredga, 1980; Zima \& Grafodatskij, 1985). According to our result and the previous studies, the migration history could be different between the Honshu and Hokkaido populations.

The Bulgarian individuals were separated into two Clusters (Ilc and Ile). Cluster IIc is distributed from Serbia in the Balkan Peninsula to Uzbekistan in Central Asia. Cluster Ile includes the individuals from Greece to Poland and could have experienced the demographic expansion shown by Fu's $F_{s}$ statistics. Populations around the Black and Caspian Seas (Turkmenistan, Ukraine, and Georgia) had higher nucleotide diversities and were differentiated from the other populations. It has been reported that the populations of the Black and Caspian Seas area could be the ancestor type of least weasel, using morphological characters (Abramov \& Baryshnikov, 2000) and mtDNA CR (Kurose et al., 2005). Our results emphasize this possibility.

\section{ACKNOWLEDGEMENTS}

We would like to thank T. Saitoh, Y. Masuda, H. Yanagawa, F. Sekiyama, M. Takahashi, M. Hisasue, the Finnish Museum of Natural History, and the Museum at the Institute of Plant and Animal Ecology (Ural Branch of the Russian Academy of Sciences) for providing samples, and $Y$. Nishita for suggestions. This study was supported in part by Joint Research Project Grants from the Japan Society of the Promotion of Science (JSPS) and the Russian Foundation for Basic Research, Russian State program AAAA-A17-117022810195-3, and a grant from the Joint Research Program of the Japan Arctic Research Network Center.

\section{ORCID}

Takuma Sato (iD https://orcid.org/0000-0002-0680-6799

Alexei V. Abramov iD https://orcid.org/0000-0001-9709-4469

Ryuichi Masuda iD https://orcid.org/0000-0002-6843-0053

\section{REFERENCES}

Abramov, A. V., \& Baryshnikov, G. F. (2000). Geographic variation and intraspecific taxonomy of weasel Mustela nivalis (Carnivora, Mustelidae). Zoosystematica Rossica, 8, 365-402.
Abramson, N. I., Petrova, T. V., Dokuchaev, N. E., Obolenskaya, E. V., \& Lissovsky, A. A. (2012). Phylogeography of the gray red-backed vole Craseomys rufocanus (Rodentia: Cricetidae) across the distribution range inferred from nonrecombining molecular markers. Russian Journal of Theriology, 11(2), 137-156. https://doi.org/10.15298/rusjt heriol.11.2.04

Atmeh, K., Andruszkiewicz, A., \& Zub, K. (2018). Climate change is affecting mortality of weasels due to camouflage mismatch. Scientific Reports, 8(1), 7648. https://doi.org/10.1038/ s41598-018-26057-5

Bazinet, A. L., Zwickl, D. J., \& Cummings, M. P. (2014). A gateway for phylogenetic analysis powered by grid computing featuring GARLI 2.0. Systematic Biology, 63(5), 812-818. https://doi.org/10.1093/sysbio/ syu031

Bergmann, C. (1847). Ueber die Verhaeltnisse der Waermeoekonomie der Thiere zu ihrer Groesse. Gottinger Studien, 3, 595-708.

Bouckaert, R., Heled, J., Kühnert, D., Vaughan, T., Wu, C. H., Xie, D., ... Drummond, A. J. (2014). BEAST 2: A software platform for Bayesian evolutionary analysis. PLoS Computational Biology, 10(4), e1003537. https://doi.org/10.1371/journal.pcbi.1003537

Dawson, N. G., Hope, A. G., Talbot, S. L., \& Cook, J. A. (2014). A multilocus evaluation of ermine (Mustela erminea) across the Holarctic, testing hypotheses of Pleistocene diversification in response to climate change. Journal of Biogeography, 41(3), 464-475. https://doi. org $/ 10.1111 /$ jbi.12221

Deffontaine, V., Libois, R., Kotlík, P., Sommer, R., Nieberding, C., Paradis, E., ... Michaux, J. R. (2005). Beyond the Mediterranean peninsulas: Evidence of central European glacial refugia for a temperate forest mammal species, the bank vole (Clethrionomys glareolus). Molecular Ecology, 14(6), 1727-1739. https://doi. org/10.1111/j.1365-294X.2005.02506.x

Dellicour, S., \& Mardulyn, P. (2014). SPADS 1.0: A toolbox to perform spatial analyses on DNA sequence data sets. Molecular Ecology Resources, 14(3), 647-651. https://doi.org/10.1111/1755-0998.12200

Dupanloup, I., Schneider, S., \& Excoffier, L. (2002). A simulated annealing approach to define the genetic structure of populations. Molecular Ecology, 11(12), 2571-2581. https://doi. org/10.1046/j.1365-294X.2002.01650.x

Excoffier, L., \& Lischer, H. E. L. (2010). Arlequin suite ver 3.5: A new series of programs to perform population genetics analyses under Linux and Windows. Molecular Ecology Resources, 10(3), 564-567. https://doi.org/10.1111/j.1755-0998.2010.02847.x

Excoffier, L., Smouse, P. E., \& Quattro, J. M. (1992). Analysis of molecular variance inferred from metric distances among DNA haplotypes: Application to human mitochondrial DNA restriction data. Genetics, 131(2), 479-491.

Frantz, A. C., McDevitt, A. D., Pope, L. C., Kochan, J., Davison, J., Clements, C. F., ... Burke, T. (2014). Revisiting the phylogeography and demography of European badgers (Meles meles) based on broad sampling, multiple markers and simulations. Heredity, 113(5), 443453. https://doi.org/10.1038/hdy.2014.45

Fu, Y. X. (1997). Statistical tests of neutrality of mutations against population growth, hitchhiking and background selection. Genetics, 147(2), 915-925.

Garrick, R. C., Bonatelli, I. A. S., Hyseni, C., Morales, A., Pelletier, T. A., Perez, M. F., ... Carstens, B. C. (2015). The evolution of phylogeographic data sets. Molecular Ecology, 24(6), 1164-1171. https://doi. org/10.1111/mec.13108

Hasegawa, M., Kishino, H., \& Yano, T. (1985). Dating of the human-ape splitting by a molecular clock of mitochondrial DNA. Journal of Molecular Evolution, 22(2), 160-174. https://doi.org/10.1007/BF021 01694

Hewitt, G. (1999). Post-glacial re-colonization of European biota. Biological Journal of the Linnean Society, 68(1-2), 87-112. https://doi. org/10.1111/j.1095-8312.1999.tb01160.x 
Hope, A. G., Waltari, E., Dokuchaev, N. E., Abramov, S., Dupal, T., Tsvetkova, A., ... Cook, J. A. (2010). High-latitude diversification within Eurasian least shrews and Alaska tiny shrews (Soricidae). Journal of Mammalogy, 91(5), 1041-1057. https://doi. org/10.1644/09-MAMM-A-402.1

Hosoda, T., Sato, J. J., Lin, L.-K., Chen, Y.-J., Harada, M., \& Suzuki, H. (2011). Phylogenetic history of mustelid fauna in Taiwan inferred from mitochondrial genetic loci. Canadian Journal of Zoology, 89, 559569. https://doi.org/10.1139/z11-029

Hosoda, T., Suzuki, H., Harada, M., Tsuchiya, K., Han, S.-H.-H., Zhang, Y., ... Lin, L.-K.-K. (2000). Evolutionary trends of the mitochondrial lineage differentiation in species of genera Martes and Mustela. Genes \& Genetic Systems, 75(5), 259-267. https://doi.org/10.1266/ggs.75.259

Jones, E. P., \& Searle, J. B. (2015). Differing Y chromosome versus mitochondrial DNA ancestry, phylogeography, and introgression in the house mouse. Biological Journal of the Linnean Society, 115(2), 348361. https://doi.org/10.1111/bij.12522

Kimura, M. (1980). A simple method for estimating evolutionary rates of base substitutions through comparative studies of nucleotide sequences. Journal of Molecular Evolution, 16(2), 111-120. https://doi. org/10.1007/BF01731581

Kimura, M. (1981). Estimation of evolutionary distances between homologous nucleotide sequences. Proceedings of the National Academy of Sciences of the United States of America, 78(1), 454-458. https://doi. org/10.1073/pnas.78.1.454

King, C. M., \& Powell, R. A. (2007). The natural history of weasels and stoats: Ecology, behavior, and management. Oxford, UK: Oxford University Press.

Kinoshita, G., Sato, J. J., Meschersky, I. G., Pishchulina, S. L., Simakin, L. V., Rozhnov, V. V., ... Suzuki, H. (2015). Colonization history of the sable Martes zibellina (Mammalia, Carnivora) on the marginal peninsula and islands of northeastern Eurasia. Journal of Mammalogy, 96(1), 172-184. https://doi.org/10.1093/jmammal/gyu021

Korsten, M., Ho, S. Y. W., Davison, J., Pähn, B., Vulla, E., Roht, M., ... Saarma, U. (2009). Sudden expansion of a single brown bear maternal lineage across northern continental Eurasia after the last ice age: A general demographic model for mammals? Molecular Ecology, 18(9), 1963-1979. https://doi.org/10.1111/j.1365-294X.2009.04163.x

Kosintsev, P. A., Gasilin, V. V., Gimranov, D. O., \& Bachura, O. P. (2016). Carnivores (Mammalia, Carnivora) of the Urals in the Late Pleistocene and Holocene. Quaternary International, 420, 145-155. https://doi. org/10.1016/j.quaint.2015.10.089

*Kurose, N., Abramov, A. V., \& Masuda, R. (2000). Intrageneric diversity of the cytochrome $b$ gene and phylogeny of Eurasian species of the Genus Mustela (Mustelidae, Carnivora). Zoological Science, 17(5), 673-679. https://doi.org/10.2108/zsj.17.673

Kurose, N., Abramov, A. V., \& Masuda, R. (2005). Comparative phylogeography between the ermine Mustela erminea and the least weasel M. nivalis of Palaearctic and Nearctic regions, based on analysis of mitochondrial DNA control region sequences. Zoological Science, 22, 1069-1078. https://doi.org/10.2108/zsj.22.1069

Kurose, N., Masuda, R., \& Yoshida, M. C. (1999). Phylogeographic variation in two mustelines, the least Weasel Mustela nivalis and the Ermine M. erminea of Japan, based on mitochondrial DNA control region sequences. Zoological Science, 16(6), 971-977. https://doi. org/10.2108/zsj.16.971

Lanave, C., Preparata, G., Saccone, C., \& Serio, G. (1984). A new method for calculating evolutionary substitution rates. Journal of Molecular Evolution, 20(1), 86-93. https://doi.org/10.1007/BF02101990

Lanfear, R., Calcott, B., Ho, S. Y. W., \& Guindon, S. (2012). Partitionfinder: Combined selection of partitioning schemes and substitution models for phylogenetic analyses. Molecular Biology and Evolution, 29(6), 1695-1701. https://doi.org/10.1093/molbev/mss020

Lebarbenchon, C., Poitevin, F., Arnal, V., \& Montgelard, C. (2010). Phylogeography of the weasel (Mustela nivalis) in the
western-Palaearctic region: Combined effects of glacial events and human movements. Heredity, 105(5), 449-462. https://doi. org/10.1038/hdy.2009.186

Lebarbenchon, C., Poitevin, F., \& Montgelard, C. (2006). Genetic variation of the weasel (Mustela nivalis) in Corsica based on mitochondrial control region sequences. Mammalian Biology, 71(3), 164-171. https ://doi.org/10.1016/j.mambio.2005.11.005

Leigh, J. W., \& Bryant, D. (2015). popart: Full-feature software for haplotype network construction. Methods in Ecology and Evolution, 6(9), 1110-1116. https://doi.org/10.1111/2041-210X.12410

Librado, P., \& Rozas, J. (2009). DnaSP v5: A software for comprehensive analysis of DNA polymorphism data. Bioinformatics, 25(11), 14511452. https://doi.org/10.1093/bioinformatics/btp187

Lorenzen, E. D., Nogues-Bravo, D., Orlando, L., Weinstock, J., Binladen, J., Marske, K. A., ... Willerslev, E. (2011). Species-specific responses of Late Quaternary megafauna to climate and humans. Nature, 479(7373), 359-364. https://doi.org/10.1038/nature10574

Magri, D., Vendramin, G. G., Comps, B., Dupanloup, I., Geburek, T., Gömöry, D., ... De Beaulieu, J. L. (2006). A new scenario for the Quaternary history of European beech populations: Palaeobotanical evidence and genetic consequences. New Phytologist, 171(1), 199221. https://doi.org/10.1111/j.1469-8137.2006.01740.x

Mandahl, N., \& Fredga, K. (1980). A comparative chromosome study by means of G-, C-, and NOR-bandings of the weasel, the pygmy weasel and the stoat (Mustela, Carnivora, Mammalia). Hereditas, 93(1), 7583. https://doi.org/10.1111/j.1601-5223.1980.tb01045.x

Marciszak, A., \& Socha, P. (2014). Stoat Mustela erminea Linnaeus, 1758 and weasel Mustela nivalis Linnaeus, 1766 in palaeoecological analysis: A case study of Biśnik Cave. Quaternary International, 339-340, 258-265. https://doi.org/10.1016/j.quaint.2013.12.058

McDevitt, A. D., Oliver, M. K., Piertney, S. B., Szafrańska, P. A., Konarzewski, M., \& Zub, K. (2013). Individual variation in dispersal associated with phenotype influences fine-scale genetic structure in weasels. Conservation Genetics, 14(2), 499-509. https://doi. org/10.1007/s10592-012-0376-4

McDevitt, A. D., Zub, K., Kawałko, A., Oliver, M. K., Herman, J. S., \& Wójcik, J. M. (2012). Climate and refugial origin influence the mitochondrial lineage distribution of weasels (Mustela nivalis) in a phylogeographic suture zone. Biological Journal of the Linnean Society, 106(1), 57-69. https://doi.org/10.1111/j.1095-8312.2012.01840.x

McDonald, R. A., Abramov, A. V., Stubbe, M., Herrero, J., Maran, T., Tikhonov, A., ... Reid, F. (2016). Mustela nivalis (Least Weasel, Weasel). The IUCN Red List of Threatened Species, 2016. https://doi. org/10.2305/IUCN.UK.2016-1.RLTS.T70207409A45200499.en

Mizumachi, K., Nishita, Y., Spassov, N., Raichev, E. G., Peeva, S., Kaneko, Y., \& Masuda, R. (2017). Molecular phylogenetic status of the Bulgarian marbled polecat (Vormela peregusna, Mustelidae, Carnivora), revealed by $Y$ chromosomal genes and mitochondrial DNA sequences. Biochemical Systematics and Ecology, 70, 99-107. https://doi.org/10.1016/j.bse.2016.10.025

Montgelard, C., Bentz, S., Tirard, C., Verneau, O., \& Catzeflis, F. M. (2002). Molecular systematics of sciurognathi (rodentia): The mitochondrial cytochrome $b$ and 12S rRNA genes support the Anomaluroidea (Pedetidae and Anomaluridae). Molecular Phylogenetics and Evolution, 22(2), 220-233. https://doi.org/10.1006/mpev.2001.1056

Obara, Y. (1991). Karyosystematics of the mustelid carnivores of Japan. Mammalian Science, 30(2), 197-220. https://doi.org/10.11238/ MAMMALIANSCIENCE.30.197

Ohshima, K. (1991). The late-Quaternary sea-level change of the Japanese Islands. Journal of Geography (Chigaku Zasshi), 100(6), 967975. https://doi.org/10.5026/jgeography.100.6_967

Patou, M. L., Chen, J., Cosson, L., Andersen, D. H., Cruaud, C., Couloux, A., ... Veron, G. (2009). Low genetic diversity in the masked palm civet Paguma larvata (Viverridae). Journal of Zoology, 278(3), 218-230. https://doi.org/10.1111/j.1469-7998.2009.00570.x 
Polyakov, A. V., Panov, V. V., Ladygina, T. Y., Bochkarev, M. N., Rodionova, M. I., \& Borodin, P. M. (2001). Chromosomal evolution of the common shrew Sorex araneus L. from the Southern Urals and Siberia in the Postglacial Period. Russian Journal of Genetics, 37(4), 351-357. https://doi.org/10.1023/A:1016690023394

Räsänen, M. E., Huitti, J. V., Bhattarai, S., Harvey, J., \& Huttunen, S. (2015). The SE sector of the Middle Weichselian Eurasian Ice Sheet was much smaller than assumed. Quaternary Science Reviews, 122, 131-141. https://doi.org/10.1016/j.quascirev.2015.05.019

Řičánková, V. P., Robovský, J., Riegert, J., \& Zrzavý, J. (2015). Regional patterns of postglacial changes in the Palearctic mammalian diversity indicate retreat to Siberian steppes rather than extinction. Scientific Reports, 5, 12682. https://doi.org/10.1038/srep12682

Rodrigues, M., Bos, A. R., Hoath, R., Schembri, P. J., Lymberakis, P., Cento, M., ... Fernandes, C. (2016). Taxonomic status and origin of the Egyptian weasel (Mustela subpalmata) inferred from mitochondrial DNA. Genetica, 144(2), 191-202. https://doi.org/10.1007/s10709-016-9889-y

Rodrigues, M., Bos, A. R., Schembri, P. J., de Lima, R. F., Lymberakis, P., Parpal, L., ... Fernandes, C. (2017). Origin and introduction history of the least weasel (Mustela nivalis) on Mediterranean and Atlantic islands inferred from genetic data. Biological Invasions, 19(1), 399-421. https://doi.org/10.1007/s10530-016-1287-y

Ronquist, F., Teslenko, M., van der Mark, P., Ayres, D. L., Darling, A., Höhna, S., ... Huelsenbeck, J. P. (2012). MrBayes 3.2: Efficient Bayesian phylogenetic inference and model choice across a large model space. Systematic Biology, 61(3), 539-542. https://doi. org/10.1093/sysbio/sys029

Sato, J. J., Wolsan, M., Prevosti, F. J., D’Elía, G., Begg, C., Begg, K., .. Suzuki, H. (2012). Evolutionary and biogeographic history of weasel-like carnivorans (Musteloidea). Molecular Phylogenetics and Evolution, 63(3), 745-757. https://doi.org/10.1016/j.ympev.2012. 02.025

Schmitt, T., \& Varga, Z. (2012). Extra-Mediterranean refugia: The rule and not the exception? Frontiers in Zoology, 9(1), 22. https://doi. org/10.1186/1742-9994-9-22

Sheffield, S. R., \& King, C. M. (1994). Mustela nivalis. Mammalian Species, 454(454), 1-10. https://doi.org/10.2307/3504183

Statham, M. J., Murdoch, J., Janecka, J., Aubry, K. B., Edwards, C. J., Soulsbury, C. D., ... Sacks, B. N. (2014). Range-wide multilocus phylogeography of the red fox reveals ancient continental divergence, minimal genomic exchange and distinct demographic histories. Molecular Ecology, 23(19), 4813-4830. https://doi.org/10.1111/mec.12898

Sukumaran, J., \& Holder, M. T. (2010). DendroPy: A Python library for phylogenetic computing. Bioinformatics, 26(12), 1569-1571. https:// doi.org/10.1093/bioinformatics/btq228

Tajima, F. (1989). Statistical method for testing the neutral mutation hypothesis by DNA polymorphism. Genetics, 123(3), 585-595.

Tamura, K., \& Nei, M. (1993). Estimation of the number of nucleotide substitutions in the control region of mitochondrial DNA in humans and chimpanzees. Molecular Biology and Evolution, 10(3), 512-526.

Tamura, K., Stecher, G., Peterson, D., Filipski, A., \& Kumar, S. (2013). MEGA6: Molecular Evolutionary Genetics Analysis version 6.0. Molecular Biology and Evolution, 30(12), 2725-2729. https://doi. org/10.1093/molbev/mst197

Tashima, S., Kaneko, Y., Anezaki, T., Baba, M., Yachimori, S., Abramov, A. V., ... Masuda, R. (2011). Identification and molecular variations of CAN-SINEs from the ZFY Gene Final Intron of the Eurasian Badgers (Genus Meles). Mammal Study, 36(1), 41-48. https://doi. org/10.3106/041.036.0105

Vereshchagin, N. K., \& Baryshnikov, G. F. (1992). The ecological structure of the "mammoth fauna" in Eurasia. Annales Zoologici Fennici, 28, 253-259. https://doi.org/10.1016/j.quaint.2004.04.011

Yamada, C., \& Masuda, R. (2010). Molecular phylogeny and evolution of sex-chromosomal genes and SINE Sequences in the Family
Mustelidae Molecular phylogeny and evolution of sex-chromosomal genes and SINE sequences in the family Mustelidae. Mammal Study, 35(1), 17-30. https://doi.org/10.3106/041.035.0102

Youngman, P. M. (1993). The Pleistocene small carnivores of Eastern Beringia. The Canadian Field-Naturalist, 107(2), 139-163.

Zima, J., \& Grafodatskij, A. S. (1985). C-heterochromatic arm variation in the weasel, Mustela nivalis (Mustelidae, Carnivora). Folia Zoologica, 34, 125-132.

Zub, K., Szafrańska, P. A., Konarzewski, M., \& Speakman, J. R. (2011). Effect of energetic constraints on distribution and winter survival of weasel males. The Journal of Animal Ecology, 80(1), 259-269. https:// doi.org/10.1111/j.1365-2656.2010.01762.x

\section{SUPPORTING INFORMATION}

Additional supporting information may be found online in the Supporting Information section at end of the article.

Alignment S1. CR for Figure S1.nexus.

Alignment S2. Cytb for Figure S2.nexus.

Alignment S3. CR and Cytb for Figure 2, S3 and S5.nexus.

Alignment S4. CR and Cytb for Figure 4.nexus.

Alignment S5. ZFY for Figure 5a.nex.

Alignment S6. ASIP for Figure 5b.nex.

Alignment S7. CR, Cytb, ASIP and ZFY for Figure S4a.nex.

Alignment S8. CR, Cytb and ASIP for Figure S4b.nex.

Alignment S9. CR, Cytb and ZFY for Figure S4c.nex.

Alignment S10. ZFY and ASIP for Figure S4d.nex.

Alignment S11. Clade I for Figure 6.nex.

Alignment S12. Clade II for Figure 6.nexus.

Figure S1. A Bayesian phylogenetic tree of mtDNA control region $(C R)$. The posterior probabilities and maximum likelihood bootstrap values are shown on nodes. The haplotype names are coincided with Table 2 and Table S1.

Figure S2. A Bayesian phylogenetic tree of mtDNA cytochrome $b$ (Cytb). The posterior probabilities and maximum likelihood bootstrap values are shown on nodes. The haplotype names are coincided with Table 2 and Table S1.

Figure S3. A maximum likelihood phylogenetic tree of concatenated mtDNA CR and Cytb. The maximum likelihood bootstrap values are shown on nodes. The haplotype names are coincided with Table 2 and Table S1.

Figure S4. The Bayesian phylogenetic tree of each pair: (a) The BI tree of concatenated all loci; (b) The BI tree of concatenated CR, Cytb and ASIP; (c) The BI tree of concatenated CR, Cytb and ZFY; (d) The $\mathrm{BI}$ tree of concatenated ZFY and ASIP. The posterior probabilities and maximum likelihood bootstrap values are shown on nodes. The haplotype names coincided with Table 2 and Table S1.

Figure S5. A Bayesian chronogram of mtDNA. The numbers at nodes are the clade numbers for clades with $\geq 0.95$ posterior probabilities, and the coalescent times are represented in table (inset). Node bars show the $95 \%$ highest posterior density of nodal age estimates. The $x$ marks indicate the individuals from the Black Sea-Caspian Sea region. 
Figure S6. The results of SAMOVA analysis for mtDNA data set. The number of group $(K)$ is shown on the $x$-axes. The $F$ values were shown on the $y$-axes. $F_{\mathrm{ct}}$; square, $F_{\mathrm{st}}$; circle, $F_{\mathrm{sc}}$; triangle.

Table S1. References from GenBank.

Table S2. Primers for PCR amplification and sequencing.

Table S3. Nucleotide substitution models for reconstructing phylogenetic trees. C1, C2 and C 3 mean the first, second and third codons How to cite this article: Sato T, Abramov AV, Raichev EG, et al. Phylogeography and population history of the least weasel (Mustela nivalis) in the Palearctic based on multilocus analysis. J Zool Syst Evol Res. 2020;58:408-426. https://doi.org/10.1111/ jzs.12330 for Cytb. 